\title{
Design associativo: análise da topografia no traçado de vias e quadras
}

\author{
Associative design: topography analysis in the layout of \\ roads and blocks
}

\section{Flávio Akihiro Takahashi \\ Ercilia Hitomi Hirota \\ Rovenir Bertola Duarte}

\section{Resumo}

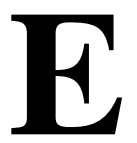

m projetos de loteamentos, há uma diversidade de requisitos normativos e de usuários envolvidos a serem considerados, entre os quais as relações entre topografia, sistema viário e custo. O uso do design associativo como instrumento para visualização dessas relações pode auxiliar na tomada de decisões e resoluções de problemas de projeto. Seguindo a metodologia descrita pelo Design Science Research, foi criado um artefato no formato de algoritmos que teve como objetivo apresentar visualmente a topografia de um terreno e permitir modificações com feedback em tempo real para o estudo de propostas de traçados de vias, partindo do pressuposto de que o custo da infraestrutura urbana é definido, predominantemente, pelo comprimento das vias. Para aplicar e avaliar o artefato, foi utilizado um empreendimento habitacional de interesse social (EHIS) como estudo de caso sobre o qual havia disponibilidade de informações necessárias para estabelecer os parâmetros, variáveis e restrições. O estudo conclui pela viabilidade da utilização de sistemas associativos como suporte às decisões de projeto, em especial nas etapas iniciais de análise de viabilidade do terreno e de concepção.

Palavras-chave: Metodologia de projeto. Design digital. Design associativo. Projeto paramétrico. Empreendimentos habitacionais de interesse social.

\section{Abstract}

In land parceling design, a diversity of normative and user requirements that should be taken into account. Those include the relationships between topography, road system and cost. In this paper, the authors propose an associative model as a tool to visualise those relationships to support the decision-making process and the resolution of design problems. Following the Design Science Research Methodology, an artifact in the form of algorithms was created to make a visual representation of the topography of a lot and to allow real time feedback for the study of road layout proposals based on the assumption that urban infrastructure costs are mainly defined by the length of the roads. To apply and evaluate the artifact, a social housing project (SHP) was chosen as the object of study for which the parameters, variables and constraints were established, based on the information collected through a literature review. The study demonstrates the feasibility of associative systems as a decision-making aid to the SHP design process, especially in the initial stages of feasibility analysis and design conception.

Keywords: Design method. Digital design. Associative design. Parametric design. Social housing projects.

Recebido em 26/09/18 


\section{Introdução}

Em metodologia de projeto, o modelo cíclico de Asimow de tomadas de decisão, apoiado em análises, sínteses e avaliações, é frequentemente citado como um mapa para o processo projetual (LAWSON, 2011). No entanto, as resoluções de problema, principalmente no início do processo de projeto, não são tão lineares e claramente apoiadas nesses estágios, pois se redefinem à medida que uma solução é adotada (SIMON, 1969). Rittel e Webber (1973), Schön (1983), Gross (1985) e Voordt e Wegen (2005) consideram muito importante a visualização de possíveis soluções nesse processo de tomada de decisão, como também enfatizam a necessidade de interação do projetista com imagens gráficas, mostrando a relevância da percepção e cognição do projetista por meios visuais no processo de projeto. Segundo Goldschmidt (2001), Johnson et al. (2008) e Ware (2008), o visual thinking contribui para a compreensão dos problemas por parte do projetista. A visualização de informações torna-se um modo de o projetista interagir de forma mais intuitiva com dados diversos em concomitância com seu processo cognitivo.

Neste trabalho, analisa-se o uso de ferramentas de design associativo na etapa inicial de concepção de projeto de empreendimentos habitacionais de interesse social (EHIS) como estratégia de visualização nas tomadas de decisão, mais especificamente decisões que envolvam a escolha do terreno (topografia) e a concepção do loteamento (arruamento). Essa etapa inicial caracteriza-se por menor disponibilidade de informações, o que aumenta a variabilidade e as incertezas do processo (TZORTZOPOULOS, 1999). O estudo relatado neste artigo aproxima essa etapa projetual e o design associativo digital como uma forma de levar em consideração um grande volume de informações sem prejuízos a uma abordagem intuitiva.

Entre os diversos estudos que abordam EHIS, Aragão (2014) e Saito (2016) analisaram os custos envolvidos na realização de um EHIS e verificaram que apenas 57\% do valor financiado pelo Programa Minha Casa, Minha Vida se refere ao custo da habitação. Cerca de $28 \%$ dos custos decorrem do terreno e da infraestrutura urbana. Ao mesmo tempo, Conceição (2015), Aragão (2014), Shigueharu (2015) e Vicentim (2015) analisaram os fatores que condicionam a permanência das famílias nesses empreendimentos e identificaram que a qualidade das vias e do convívio social, a disponibilidade de áreas comerciais e áreas verdes, e a segurança do patrimônio e das pessoas agregam muito valor para as famílias de baixa renda.
Tem-se como hipótese, portanto, que, para melhorar a qualidade de EHIS, é necessário aumentar a eficiência da tomada de decisões na etapa inicial de planejamento do empreendimento, que envolve definição de terreno, projeto de loteamento e concepção do EHIS.

Esta pesquisa em design associativo foi baseada em um modelo paramétrico que auxilia na visualização de dados e na exploração de soluções para a tomada de decisões no desenvolvimento do projeto de um EHIS, no caso o parcelamento do solo de área destinada a habitações unifamiliares. Esse modelo foi desenvolvido e testado como um artefato, de acordo com a metodologia do Design Science Research (DSR), com a finalidade de conceber um conhecimento sobre como projetar e compreender o processo cognitivo por meio do qual o projeto foi elaborado (DRESCH; LACERDA; ANTUNES, 2015).

\section{Referencial teórico}

Arquitetura digital, ou design digital, é definida por Kolarevic (2000) como processos baseados em computador para a criação e a transformação da forma, não apenas como ferramenta de representação. Oxman (2005) e Kolarevic (2000) apresentam uma sistematização, respectivamente, na forma de modelos metodológicos e classificação a partir dos usos e produtos gerados sob a designação de design digital. Ambas as sistematizações convergem para a existência de uma categoria denominada formação digital, na qual, com base em técnicas de design paramétrico (OXMAN, 2005), destaca-se o design associativo. No design associativo as relações entre objetos são explicitamente descritas, estabelecendo interdependências entre eles, o que implica que as mudanças de valores em determinado parâmetro gerem múltiplas variações enquanto mantêm as condicionantes das relações topológicas (OXMAN, 2005).

No design associativo são declarados os parâmetros do objeto e suas relações de forma explícita, estabelecendo interdependências entre os objetos (KOLAREVIC, 2000; OOSTERHUIS et al., 2004; OXMAN, 2005; ALVARADO; MUÑOZ, 2012), de forma que a modificação dos valores de um parâmetro se propaga pelos objetos, podendo simular diversas propostas e manter as condições determinadas entre os parâmetros (MEREDITH, 2008; NOJIMOTO; TRAMONTANO; ANELLI, 2011). Assim, a modelagem paramétrica proporciona um meio para organização, visualização e controle dos dados e requisitos. 
Para o estudo, cujos resultados são apresentados neste artigo, considerou-se que os sistemas associativos configuram uma transição do uso predominante da tecnologia CAD, observado atualmente para sistemas generativos evolutivos, e que sua utilização pode ser a transição para métodos mais avançados no futuro. Essa abordagem teve como intuito uma maior aproximação da forma como os projetistas trabalham atualmente. Por essa razão, parte da modelagem desenvolvida no estudo empírico foi realizada de maneira manual, em que o projetista tem controle direto sobre a forma, podendo modificá-la mediante a visualização de resultados da interação de parâmetros.

\section{Método}

O método de pesquisa utilizado foi o Design Science Research (DSR), ou pesquisa construtiva, que, segundo Lukka (2003), é um procedimento de pesquisa para a produção de artefatos inovadores com a intenção de resolver problemas do mundo real e também fazer uma contribuição teórica para a área em que é aplicada. Os principais requisitos para a adoção do DSR são o foco em problemas reais que possam ser resolvidos na prática, a compreensão geral sobre o tópico, a produção de um artefato para a resolução do problema, a tentativa de implementação do artefato desenvolvido para avaliar sua aplicação na prática, o envolvimento e a cooperação entre o pesquisador e profissionais, a ligação explícita com o conhecimento teórico e a reflexão das conclusões empíricas de volta para a teoria (LUKKA, 2003).

O trabalho foi desenvolvido seguindo as etapas apresentadas na Figura 1. Partiu-se de uma revisão bibliográfica sobre requisitos para projeto de EHIS e aplicação do artefato nas etapas iniciais do desenvolvimento da implantação do empreendimento. Em seguida, para a produção de uma construção inovadora para a resolução do problema, foi desenvolvido um artefato baseado em modelo algoritmo que produzisse uma análise topográfica visando racionalizar custos de infraestrutura urbana, qualificar traçados das vias e definir a constituição das quadras. O artefato foi desenvolvido por meio de um estudo exploratório em uma área localizada em Londrina e avaliado por um engenheiro civil, empresário dedicado à produção de EHIS. Ao final foram analisadas as contribuições teóricas e a aplicabilidade da solução desenvolvida, buscando entender se o artefato conseguiu resolver o problema do mundo real.

\section{Compreensão sobre o tópico}

Esta etapa foi marcada por uma revisão bibliográfica que permitiu:

(a) compreender os conceitos, ferramentas e métodos existentes para processamento, gerenciamento e hierarquização de requisitos;

(b) identificar e analisar processos de projeto voltados para organização de requisitos e criação de diretrizes básicas de concepção;

(c) identificar ferramentas e software existentes que integram esses parâmetros de forma a criar modelos que sejam coerentes e não conflitantes entre si; e

(d) determinar um processo base e diretrizes para a implantação do sistema paramétrico.

A coleta de dados foi feita a partir da análise de normas e leis que regem o parcelamento, uso e ocupação do solo do município, e de dados secundários em estudos acadêmicos voltados para a proposição de diretrizes qualitativas para EHIS, em especial autores como Aragão (2014), Ayoub (2014), Shigueharu (2015), Vicentim (2015) e Saito (2016), que desenvolveram estudos, de forma integrada, em um mesmo EHIS. O objetivo desse levantamento foi buscar requisitos de projeto de EHIS para apoiar o desenvolvimento do modelo.

\section{Elaboração do modelo}

$\mathrm{O}$ artefato desenvolvido consiste em um modelo parametrizado de loteamento para EHIS a partir da formulação de algoritmos para avaliação da topografia do terreno e visualização de relações entre a topografia e o sistema viário.

Figura 1 - Delineamento da pesquisa

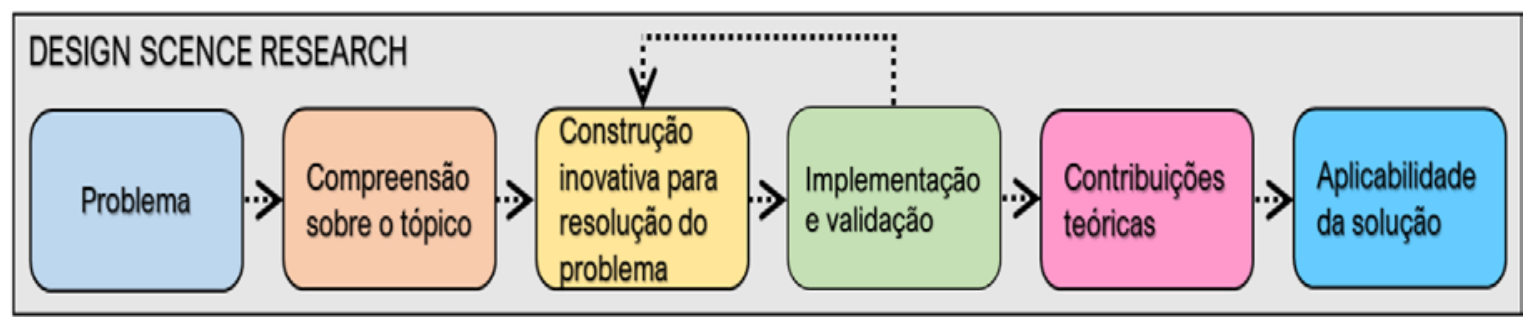


Para a elaboração do modelo, houve a necessidade de se obterem dados reais de um EHIS, de forma a também possibilitar, ao final, uma avaliação de utilidade do modelo proposto. Os requisitos e diretrizes coletados foram organizados, por semelhança ou complementação de conteúdo das fontes, na forma de um mapa (Figura 3), no qual foram estabelecidas hierarquia e relações de interdependência entre os elementos e determinadas restrições, parâmetros e variáveis, que foram aplicadas no modelo e utilizadas para o lançamento de vias.

O modelo foi desenvolvido nas seguintes etapas:

(a) escolha das ferramentas conforme descrito na seção Ferramentas, mais adiante;

(b) seleção de restrições e variáveis para aplicação no modelo;

(c) formulação do algoritmo para avaliação de topografia, mapeando e quantificando inclinações;

(d) aplicação do algoritmo em um estudo de caso (terreno destinado a EHIS);

(e) formulação do algoritmo para avaliação do sistema viário em relação à topografia;

(f) aplicação do algoritmo no caso estudado considerando-se as vias de acordo com o projeto executado;

(g) organização dos resultados em planilhas e geração de gráficos apresentando as inclinações das vias projetadas com relação ao terreno natural, visando avaliar os impactos da proposta nos custos de execução das vias;

(h) aplicação do algoritmo no caso estudado, com lançamento de vias propostas pelo autor a partir de diretrizes qualitativas e do feedback visual em tempo real das vias na topografia;

(i) organização dos resultados em planilhas e geração de gráficos, apresentando as inclinações das vias projetadas com relação ao terreno natural, visando avaliar os impactos da proposta nos custos de execução das vias; e

(j) conhecimento das aplicações e limitações do design associativo na etapa de concepção do processo de projeto arquitetônico, caracterizando esta etapa quanto ao escopo de decisões a serem tomadas.

\section{Avaliação}

Após a construção do artefato foi realizada a avaliação dele, pois, como March e Smith (1995) explicam, um modelo deve ser avaliado no DSR segundo sua fidelidade com o fenômeno real, a plenitude, o nível de detalhe, a operacionalidade, a robustez, a consistência interna, a generalidade, a eficiência e a facilidade de uso.

O modelo foi avaliado em duas etapas: a primeira, feita pelo próprio autor no desenvolvimento e formulação do modelo, e a segunda, por um engenheiro civil, empresário, selecionado devido a sua forte atuação profissional, há cerca de 25 anos, no desenvolvimento de EHIS, em Londrina e região, e que vem colaborando com pesquisas em torno do objeto de estudo, e a sua disponibilidade para participar da avaliação do modelo para considerações quanto à utilidade, aplicabilidade e eficácia. Exerce a função de diretor técnico de empresa privada na área da construção civil e é responsável pelo empreendimento adotado como caso na pesquisa.

\section{Desenvolvimento}

\section{Ferramentas}

Para o desenvolvimento do estudo empírico, foram utilizados dois conjuntos de softwares e plug-ins. $\mathrm{O}$ primeiro conjunto é composto de software para registro e organização de informações coletadas, que foram utilizadas como base para a modelagem, como arquivos de texto, contendo leis e diretrizes provenientes de pesquisas (Microsoft Word e arquivos PDF), planilhas e tabelas (Microsoft Excel), e dados topográficos, geométricos e vetoriais (Autodesk Autocad). O segundo conjunto inclui os softwares e plug-ins para a modelagem paramétrica, visualização e simulação, que foi feita com a utilização do Dynamo, que trabalha como uma extensão do Autodesk Revit, e também permite a interação, utilizando e gerando dados, com planilhas de Microsoft Excel.

A escolha do plug-in e dos softwares decorreu da familiaridade dessas interfaces por projetistas, já que a plataforma criada pela Autodesk para o software Autocad é muito disseminada. Uma premissa adotada no desenvolvimento do modelo é que ele fosse criado de modo que não exigisse conhecimento aprofundado do usuário sobre a ferramenta, facilitando sua implementação e utilização.

\section{Coleta e análise de dados Informações do EHIS}

O terreno utilizado para o desenvolvimento deste estudo exploratório foi destinado a um EHIS composto de 220 unidades residenciais caracterizadas como habitações térreas unifamiliares, em uma área de 121.000,00 m².

O perímetro do terreno desenvolve-se na forma de um trapézio, com o lado sul de maneira irregular, 
devido ao fundo de vale. Sua topografia se desenvolve com dois sentidos de inclinação, sendo a parte norte com a declividade no sentido leste e a parte sul voltada para o fundo de vale (Figura 2).

\section{Diretrizes qualitativas}

As diretrizes qualitativas foram extraídas de pesquisas realizadas em outro empreendimento, na mesma localidade e com o mesmo contexto. Segundo Aragão (2014), três itens relacionados ao terreno influenciam no custo do EHIS: a condição física do terreno, por definir custos de infraestrutura; a localização do terreno em relação a áreas urbanas consolidadas, por afetar o custo dos equipamentos institucionais com a reserva de terreno para serviços comunitários; e, por fim, o custo do terreno, que, devido à supervalorização de áreas centrais e áreas consolidadas, leva à instalação de EHIS cada vez mais distantes das estruturas urbanas existentes.

Saito (2016), ao propor uma sistemática para análise do custeio-meta para EHIS, apontou indicadores para estimativa de custos de infraestrutura urbana com base em revisão de literatura. Grande parte desses indicadores tem como parâmetro o comprimento de vias projetadas para o loteamento, o que implica a prevalência do efeito desse parâmetro sobre os custos dos elementos da infraestrutura urbana. Dessa forma, no desenvolvimento do modelo, o comprimento de vias foi adotado como elemento fundamental na análise de custos.

Shigueharu (2015) sintetiza diretrizes projetuais para favorecer o fortalecimento do senso de comunidade em áreas de habitação de interesse social a partir de conceitos de caminhabilidade e da definição do uso solo. Os resultados desse estudo são considerados importantes porque afetam o índice de retenção das famílias no EHIS: quanto maior 0 senso de comunidade, menor a probabilidade de que as famílias abandonem o imóvel antes da quitação do financiamento. Shigueharu (2015) propõe a preferência na construção de vias estreitas para diminuir o fluxo e velocidade de veículos, de forma a privilegiar o pedestre. Além disso, pela dimensão do empreendimento e configuração das vias estruturais, arteriais e coletoras existentes, apenas vias locais são lançadas no projeto.

\section{Figura 2 - Planta do terreno com topografia e cortes}

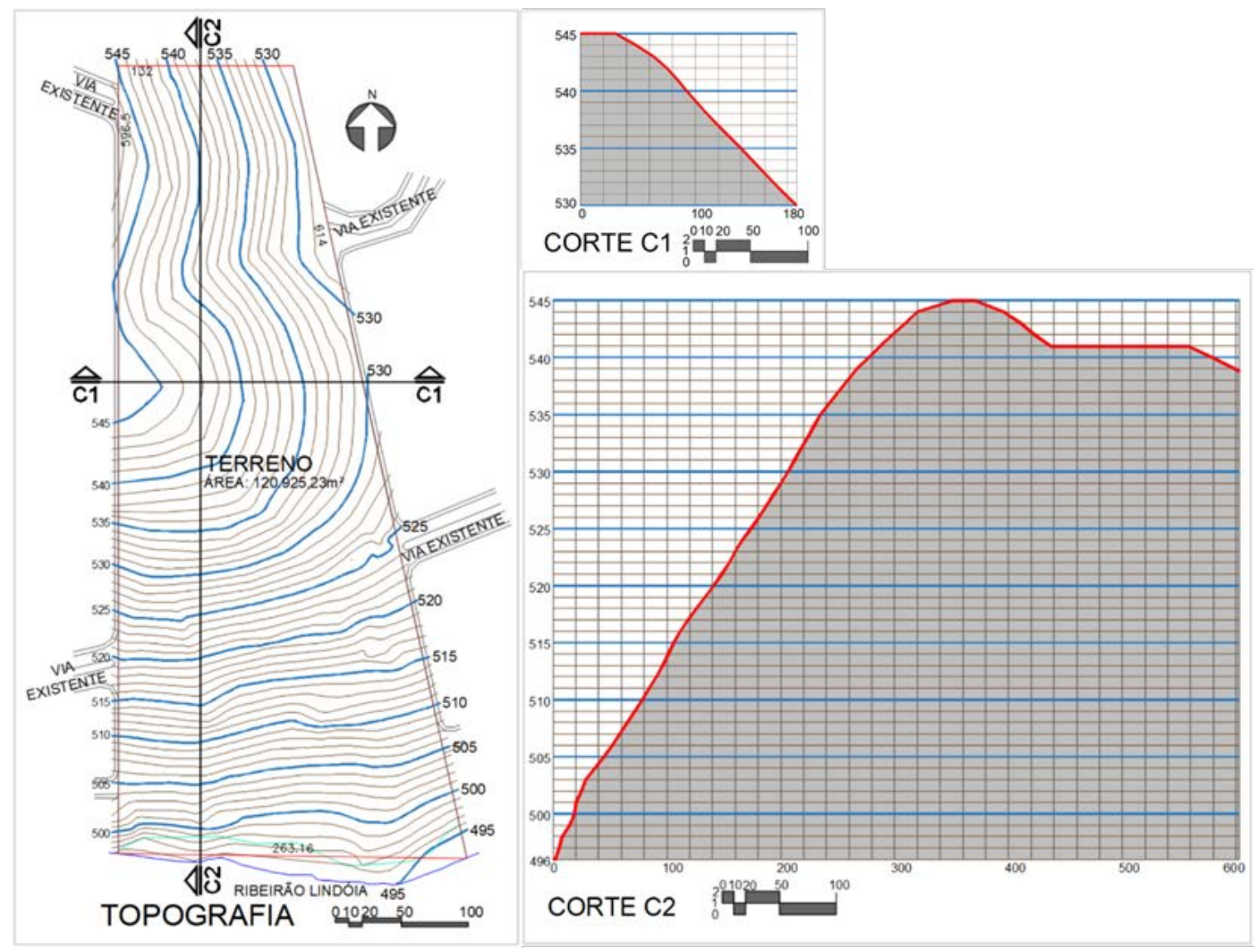


A pesquisa de Vicentim (2015), na qual os estabelecimentos comerciais informais de um EHIS local foram identificados e monitorados, estabelece diretrizes para o controle do comércio de maneira indiscriminada pela área residencial. Por fim, Ayoub (2014) compila orientações de projeto para espaços livres de uso público em EHIS.

\section{Requisitos de leis municipais}

Para o levantamento de requisitos de origem legal, que se caracterizam como diretrizes prescritivas para implantação do empreendimento, foram consultadas leis municipais de parcelamento do solo, lei de uso e ocupação do solo, projeto de lei das zonas especiais de interesse social, lei do sistema viário e código ambiental do município.

\section{Organização das informações para elaboração do modelo}

Para a criação dos algoritmos foi necessário conhecer as relações de interdependência entre parâmetros para determinação das associações. Para tanto, os requisitos e diretrizes coletados foram organizados, por semelhança ou complementação de conteúdo das fontes, na forma de um mapa (Figura 3), no qual foram estabelecidas hierarquia e relações de interdependência entre os elementos. O mapa se configura da esquerda para a direita, iniciado pela escolha do terreno e seus requisitos, que depois são ligados a outros blocos (vias, comércio, quadras, lotes, áreas institucionais e unidades habitacionais), cada bloco com seus respectivos requisitos vindo de diferentes fontes $\mathrm{e}$ diferenciados por cores, conforme a Figura 4.

Ao lançar todas as restrições de vias e preservação ambiental (Figura 4), a área útil do terreno foi reduzida para $70.495,96 \mathrm{~m}^{2}$, ou $58,29 \%$ da área total. Segundo a Lei $n^{\circ} 11.672 / 2012$, áreas de domínio público deverão corresponder a, no mínimo, 35\% da área do terreno. Para viabilizar o empreendimento, é necessário que o parcelamento do solo permita a utilização do máximo da área restante para as unidades habitacionais, requerendo, portanto, o lançamento do menor número de vias locais possível.

\section{Figura 3 - Mapeamento de requisitos}

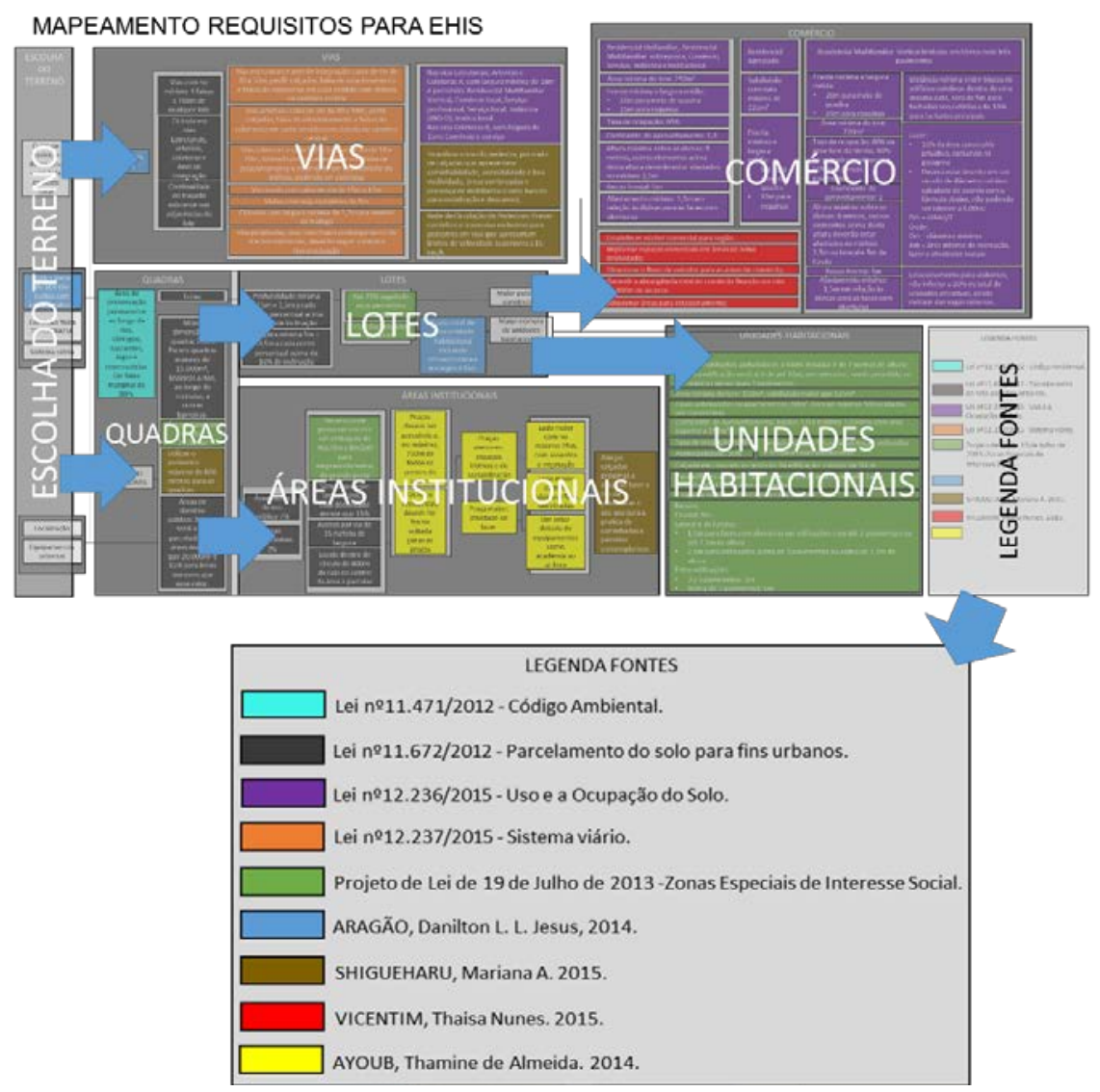


Figura 4 - Restrições

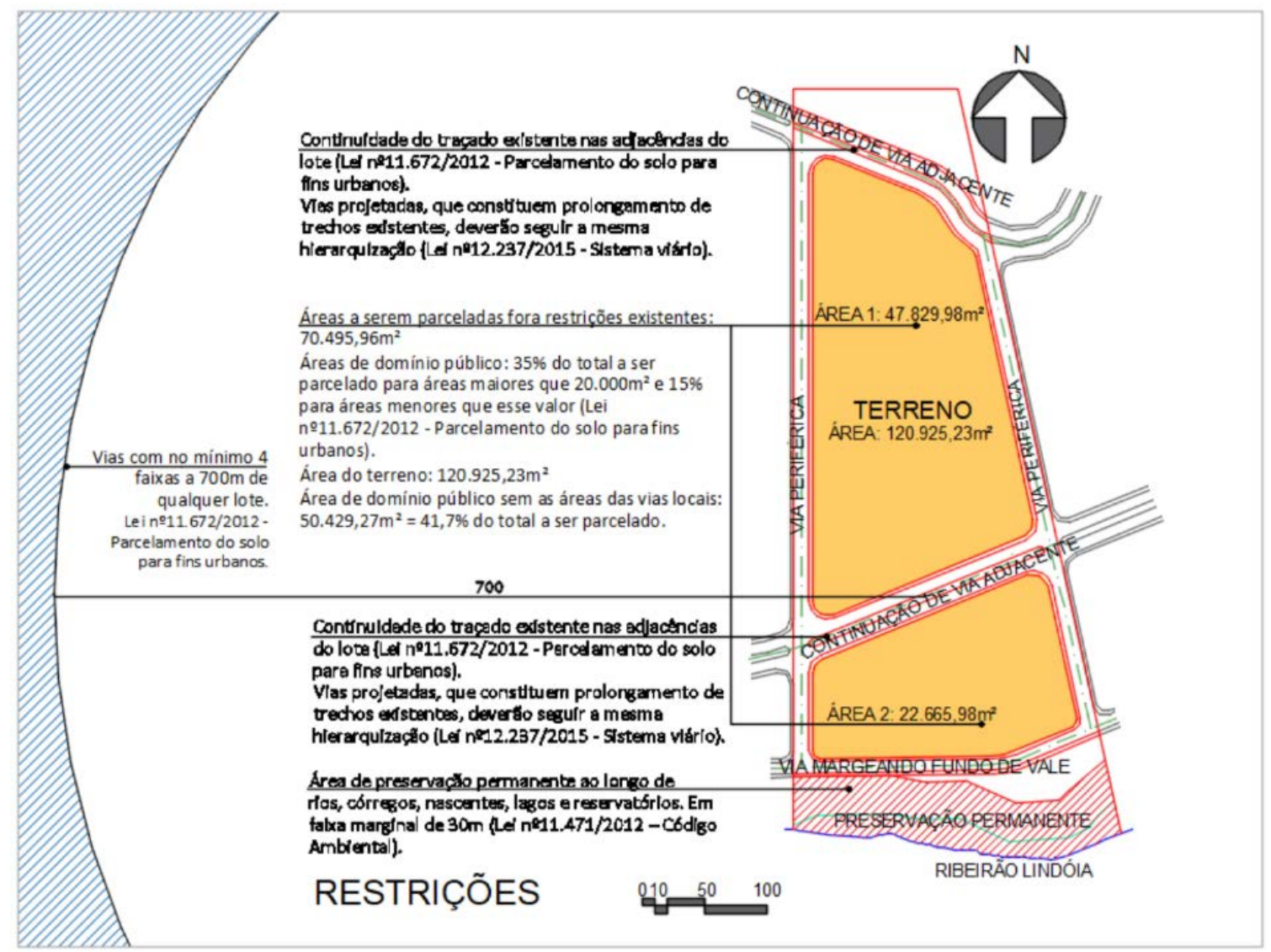

\section{Estabelecimento de parâmetros e variáveis}

Para a análise do sistema viário com a topografia, recorte adotado neste estudo, os requisitos e as diretrizes que auxiliaram no lançamento das vias (Figura 17) são apresentados no Quadro 1, e os requisitos e as diretrizes utilizados diretamente nos algoritmos (Figuras 6, 12 e 16) são apresentados no Quadro 2.

Há relação direta entre sistema viário, topografia e custos: quanto mais inclinadas e mais extensas forem as vias, maior será o custo de infraestrutura devido à maior movimentação de terra, aumento do uso de contenção nas divisas e aumento do número de poços de visita nas redes de água e esgoto. Além disso, a redução da declividade das vias favorece a caminhabilidade, descrita por Shigueharu (2015). O modelo foi, então, elaborado a partir da necessidade de visualização da relação entre o sistema viário com a topografia, conforme descrito a seguir.

\section{Elaboração do modelo}

O artefato desenvolvido consiste em um modelo parametrizado de loteamento para EHIS a partir da formulação de dois algoritmos: o primeiro para avaliação da topografia do terreno e o segundo para visualização de relações entre a topografia e o sistema viário.

\section{Algoritmo para avaliação da topografia do terreno}

Primeiramente foi desenvolvido um algoritmo para coloração de objetos (linhas e superfícies) com inclinação em relação a um plano horizontal com o objetivo de analisar a inclinação do sistema viário. Esse algoritmo também pode ser utilizado em uma etapa anterior, auxiliando na escolha do terreno.

O modelo proposto tem como base a análise de dados topográficos a partir de um levantamento topográfico. No entanto, na eventualidade de inexistência desse levantamento, nesta etapa é possível fazer uso de outras fontes baseadas em técnicas de aerofotogrametria, como cartas topográficas, fornecidas pela prefeitura do município ou pelo Instituto Brasileiro de Geografia e Estatística (IBGE), Google Earth em conjunto com o software Sketchup, e ainda dados do Open Street Map (OSM), que coleciona um acervo de dados geográficos e os divulga de forma gratuita. 


\section{Quadro 1 - Requisitos que auxiliaram no lançamento das vias}

Entre $16 \%$ e $34 \%$ do custo total do empreendimento para infraestrutura

Nas vias estruturais, arteriais e coletoras A, com largura mínima de 18 m são permitidos: residencial multifamiliar vertical; comércio local, serviço profissional, serviço local, indústria (IND-D), institucional.

Nas vias coletoras B, com largura de 15 m, comércio e serviço.

Até 25\% seguindo usos permitidos da ZR3.

Garantir a abrangência total do comércio, fixando um raio de $400 \mathrm{~m}$ de alcance.

O custo total de uma unidade habitacional incluindo infraestrutura e encargos é fixo.

Área de domínio público: 50\% da área em terreno único, com declividade menor que 15\%.
Considerando um custo e lucros constantes para o empreendimento, quanto menor o custo de infraestrutura, mais recursos são possíveis de ser alocados para a unidade habitacional.

Possibilidade de se locar estabelecimentos comerciais no empreendimento.

É necessário o maior número de unidades habitacionais possível.

Locar espaços públicos em local com menor declividade no terreno.

\section{Quadro 2 - Requisitos e diretrizes utilizados para desenvolvimento dos modelos}

\begin{tabular}{|c|c|}
\hline REQUISITO E DIRETRIZES & UTILIZAÇÃO \\
\hline Condição física do terreno: topografia. & Análise de inclinação da topografia do terreno. \\
\hline $\begin{array}{l}\text { Incentivar o uso do pedestre por meio de calçadas } \\
\text { que apresentem caminhabilidade, acessibilidade e } \\
\text { boa declividade, áreas sombreadas e presença de } \\
\text { mobiliários (como bancos para socialização e } \\
\text { descanso). }\end{array}$ & $\begin{array}{l}\text { Lançamento de vias que tenham baixa } \\
\text { declividade. }\end{array}$ \\
\hline $\begin{array}{l}\text { Área mínima do lote: } 150 \text { m², subdivisão maior } \\
\text { que } 125 \mathrm{~m}^{2} \text {. }\end{array}$ & $\begin{array}{l}\text { Como visto na tabela anterior, é necessário o } \\
\text { maior número possível de unidades } \\
\text { habitacionais. Utilizando a área mínima do lote } \\
\text { como fixa, é possível ter uma relação entre o } \\
\text { comprimento e a largura do terreno para } \\
\text { determinar o tamanho da quadra. }\end{array}$ \\
\hline $\begin{array}{l}\text { Testada mínima: } 5 \text { m para habitação unifamiliar e } \\
4 \text { m para casas sobrepostas. }\end{array}$ & Valores mínimos para largura dos lotes. \\
\hline
\end{tabular}

Para a formulação do modelo foram definidos alguns objetivos:

(a) demarcação da topografia segundo gradiente de inclinação;

(b) cálculo de áreas segundo a inclinação de topografia (ex.: áreas com mais de 30\% de inclinação e sua proporção em relação à área total do terreno); e

(c) possibilidade de exportar valores em planilhas de Excel para vincular com outros valores, como custo.
Foram utilizados dados topográficos junto com parâmetros para o cálculo da inclinação relacionando com cores para uma visualização geral do terreno. Os dados topográficos foram importados (no caso, o levantamento topográfico em Autocad) para o software Revit, e a superfície topográfica foi criada com o uso da ferramenta toposurface do próprio Revit, conforme a Figura 5.

O primeiro algoritmo é composto de cinco passos, apresentados em graphic algorithms na Figura 6 e detalhados passo a passo a seguir. 
Figura 5 - Importação de curvas topográficas no Revit e criação de superfície

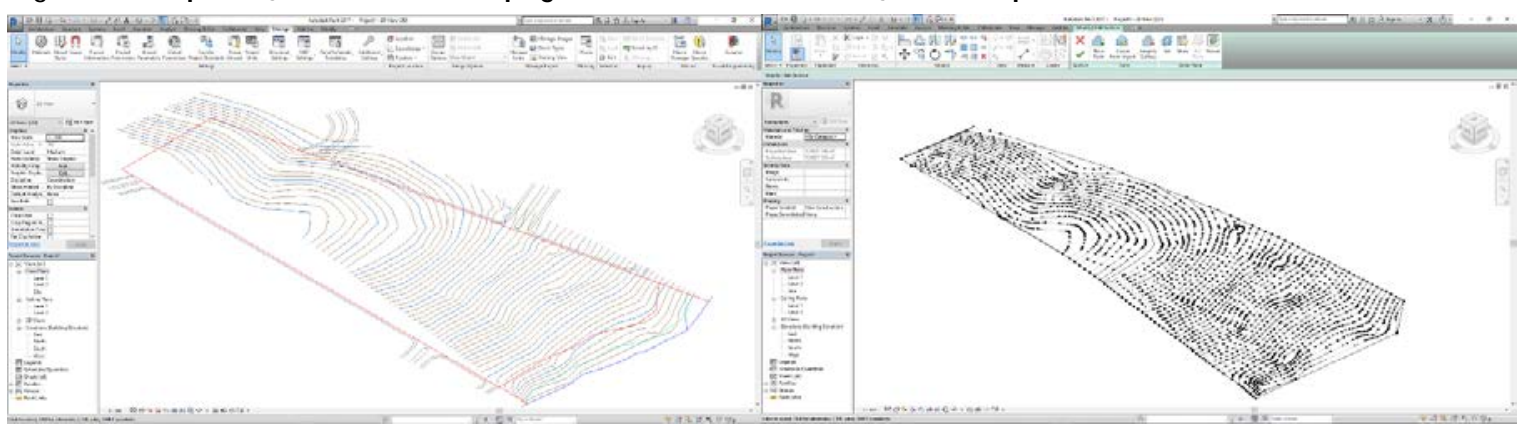

Figura 6 - Algoritmo para mapeamento de inclinações da topografia do terreno

(1)

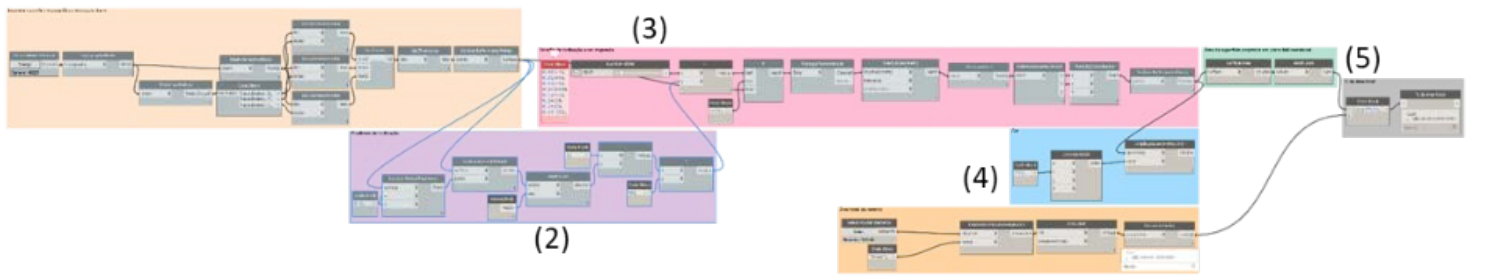

Importação e processamento da superfície topográfica no plug-in Dynamo

Primeiro é feita a seleção da malha topográfica no ambiente de visualização gráfica do Dynamo. Para que o algoritmo funcione com a malha topográfica selecionada do Revit, é necessário convertê-la em uma superfície. Para isso foi feita a desconstrução da malha em pontos e, posteriormente, a geração da superfície a partir dos pontos organizados, conforme a Figura 7.

\section{Cálculo da inclinação da superfície}

Em cada face triangular é traçado um vetor normal a sua face e calculado seu ângulo (Figura 8). O resultado da inclinação é utilizado como valor para selecionar o intervalo de inclinação a ser calculado.

\section{Seleção do intervalo de inclinação desejada} em porcentagem

Foi feita uma tabela de conversão dos valores resultantes para inclinação em porcentagem. Ao lado desse gráfico foi proposto um slider para seleção do valor do intervalo de inclinação desejada para cálculo (Figura 9). A superfície selecionada resultante foi então projetada em uma superfície horizontal.

Cálculo da área da superfície horizontal resultante da projeção da superfície com inclinação selecionada

Seleção de uma cor para destacar a superfície (vermelho).
Seleção da área total do terreno para cálculo de porcentagem.

Cálculo da porcentagem da superfície destacada em relação a área total do terreno

Após a seleção de cada intervalo de inclinação desejada, é possível fazer uma composição das áreas e valores resultantes em (l), exportados para uma planilha de Excel, como visto na Figura 10.

\section{Resultados}

Com o resultado do modelo é possível visualizar todos os intervalos de inclinação e sua respectiva proporção, fornecendo informações importantes para uma avaliação preliminar dos custos de movimentação de terra e de execução de infraestrutura urbana no terreno analisado. Esse mapeamento pode também ser utilizado como referência para o atendimento a diretrizes de projeto vinculadas ou restringidas pela declividade do terreno, como a Lei ${ }^{\circ}$ 11.672/2012 (local), que trata do parcelamento do solo. Essa lei estabelece que $50 \%$ das áreas destinadas a uso público devem estar em terreno com declividade inferior a $15 \%$. Como exemplo, no terreno estudado essas áreas poderiam ser projetadas na parte superior da via estrutural, visível pelas colorações azul clara, rosa e cinza, que demarcam áreas com inclinação mais baixa.

\section{Algoritmo para avaliação do sistema viário em relação a topografia}

Para a criação do segundo algoritmo foram definidos alguns requisitos: 
(a) demarcação das vias segundo gradiente de inclinação através de cores;

(b) separação da via em segmentos por intervalos de inclinações e posterior contabilização, pois o comprimento e a inclinação são diretamente proporcionais ao custo;

(c) possibilidade de exportar valores em planilhas de Excel para vincular com outros valores, por exemplo, com o custo; e (d) possibilidade de se ajustarem vias de forma a avaliar diferentes cenários com a visualização dos resultados.

Para o primeiro traçado das vias foi utilizado o projeto atualmente executado no local (Figura 11).

O algoritmo para análise foi criado para visualizar e quantificar suas inclinações em sete etapas, representadas na Figura 12.

\section{Figura 7 - Resultado da separação dos pontos da malha topográfica}
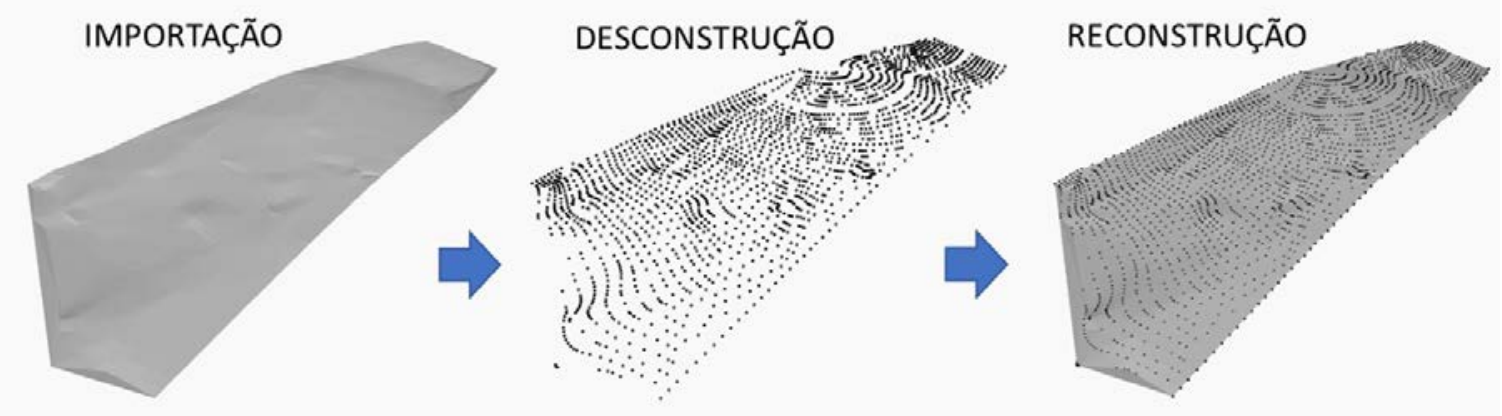

Figura 8 - Resultado da separação dos pontos da malha topográfica

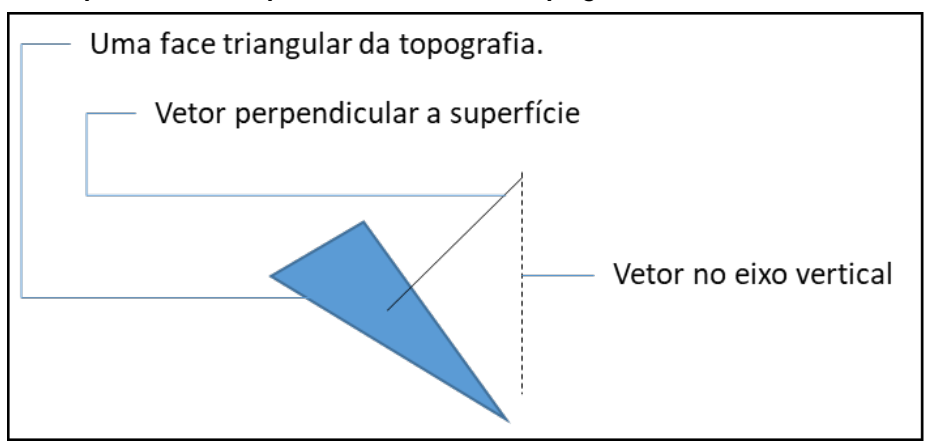

Figura 9 - Seleção da superfície através do valor da inclinação

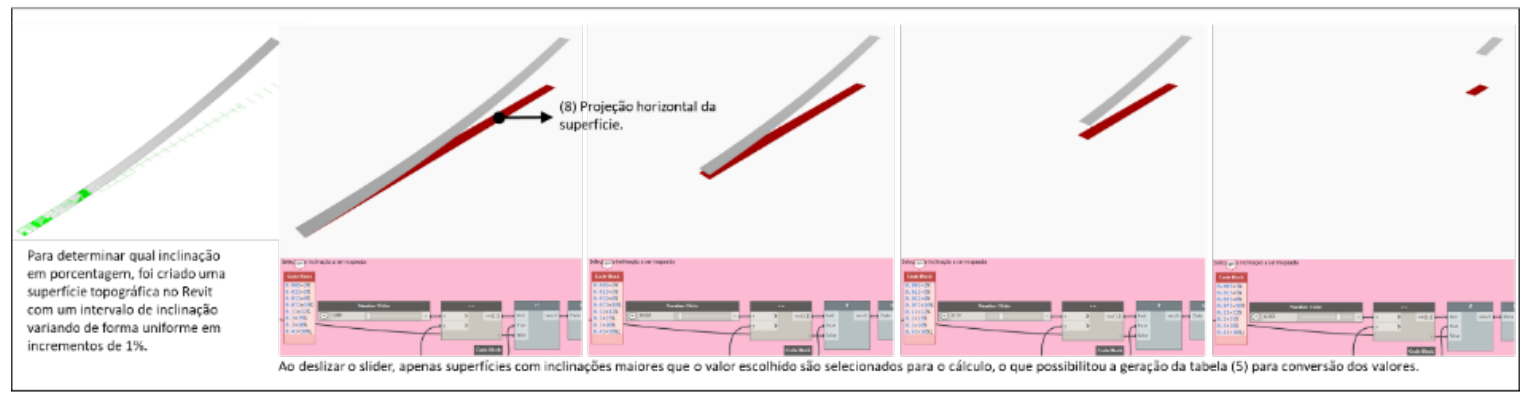


Figura 10 - Composição de todos os intervalos lançados e gráfico resultante de valores exportados para o Excel
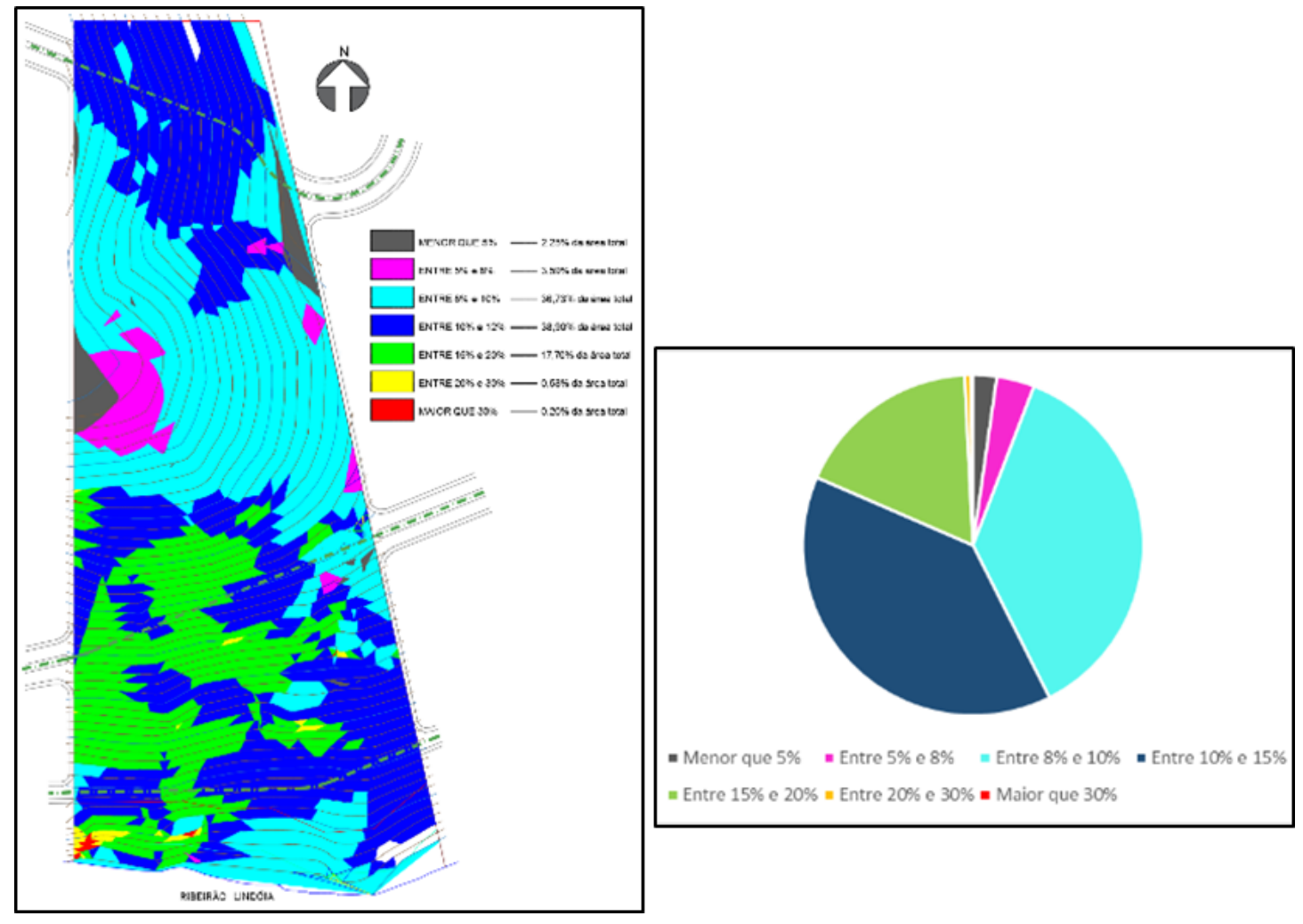

Figura 11 - Projeto atualmente executado no local

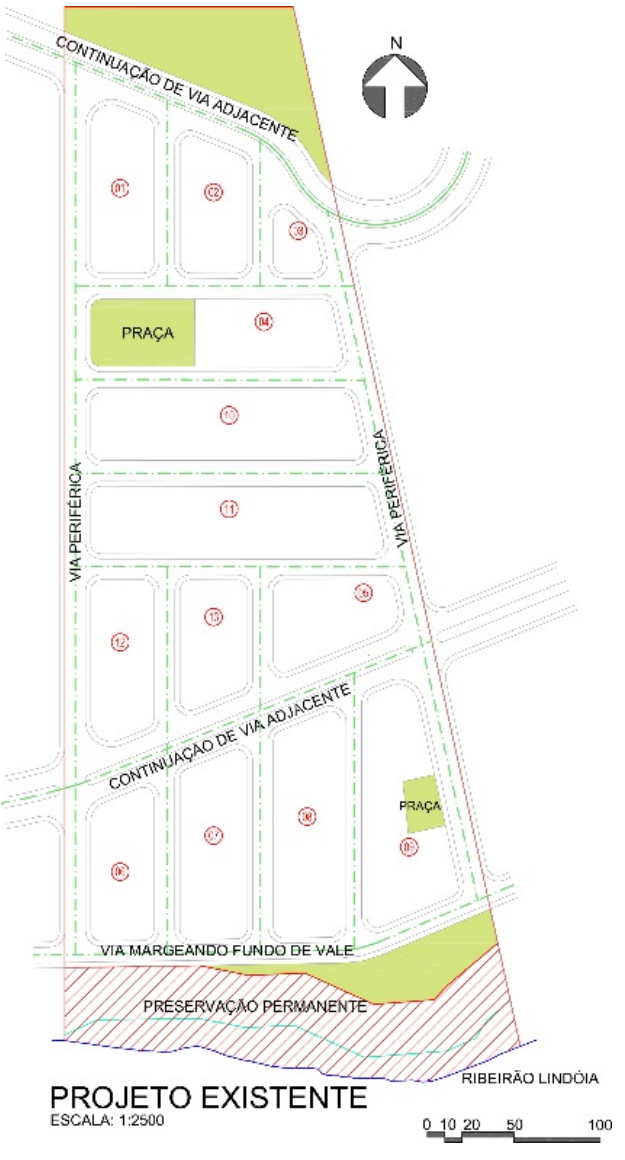


Figura 12 - Algoritmo para análise de inclinações das vias

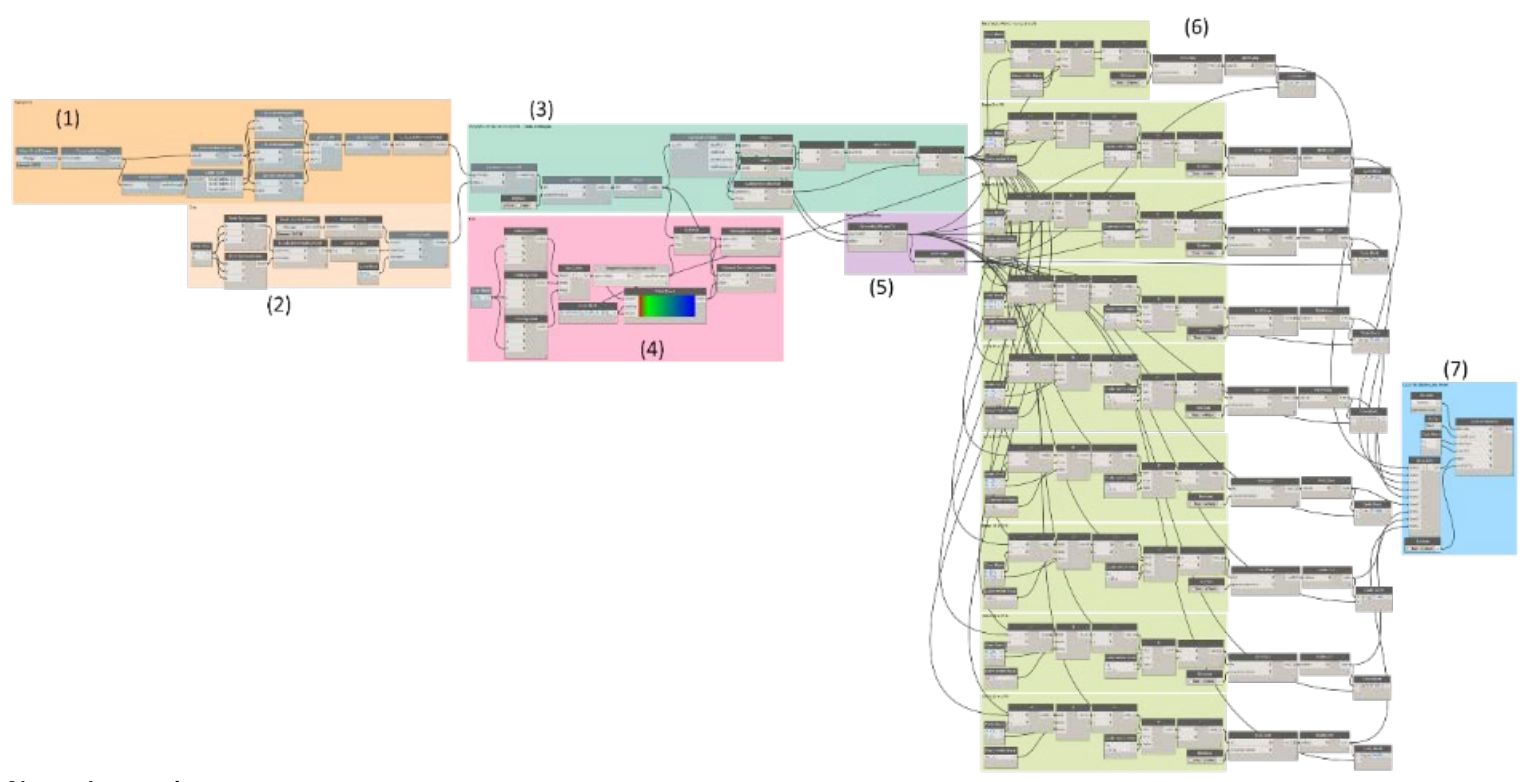

Nota: Legenda:

1. Processamento dos dados topográficos, transformando a superfície do terreno em faces triangulares, como no algoritmo anterior.

2. Processamento dos eixos das vias, importando as linhas em formato .dwg no Revit e carregando essa geometria no Dynamo.

3. Interseção da superfície topográfica com a via. Cada trecho da interseção com inclinações distintas é separado por seus pontos inicial e final para o cálculo da distância horizontal entre os pontos inicial e final do trecho da via, bem como da diferença de altitude entre os pontos inicial e final do trecho da via. É possível então, com a distância horizontal e a altura, calcular a inclinação em porcentagem da via. Como o eixo da via já é um elemento em duas dimensões, não é preciso utilizar um vetor.

4. Cálculo das inclinações da via e sua coloração correspondente.

5. Somatória do comprimento horizontal de todos os trechos para cálculo de porcentagem no final do processo.

6. Contabilização do comprimento de trechos segundo o intervalo de inclinação.

7. Exportação do resultado para células de uma planilha de Excel, que já pode conter fórmulas e gráficos que utilizam os valores delas. Produzindo formas de organização, vizualização e apresentação das inclinações das vias proj etadas com relação ao terreno natural, visando avaliar os impactos da proposta nos custos de execução das vias.

Primeiro, o algoritmo foi aplicado em uma superfície-teste com a inclinação aumentando $1 \%$ a cada trecho com o objetivo de validar os resultados do algoritmo (Figura 13). Após a validação, foram importados no algoritmo o terreno e as vias, obtendo-se os resultados vistos na Tabela 1 e nas Figuras 14 e 156.

Para simplificar os dados de entrada no algoritmo, permitindo, assim, maior velocidade na análise de propostas de projeto, foram utilizados apenas os eixos das vias, descartando a necessidade de se lançar um projeto detalhado, com largura das vias e calçadas. Outra vantagem do lançamento apenas dos eixos das vias é o fato de poderem ser lançadas em CAD, reduzindo dificuldades por parte de projetistas não familiarizados com o software e o plug-in, o que facilitaria sua implantação com pouco treinamento e baixo impacto no funcionamento das empresas e instituições.

Como alternativa ao resultado do projeto executado foi feito o lançamento de outro cenário modificando-se vias a partir da visualização do resultado obtido na primeira tentativa. Para o lançamento das vias foram utilizados algoritmos com funções matemáticas para determinar o tamanho do lote de acordo com sua largura, comprimento (Figura 16) e consequentes dimensões de quadras e distanciamento de vias.

Para esse novo lançamento de vias (Figura 17) foram adotadas algumas diretrizes a partir do mapeamento de requisitos (Figura 3 e Quadro 1) restrições (Figura 4). 
Figura 13 - Superfície-teste

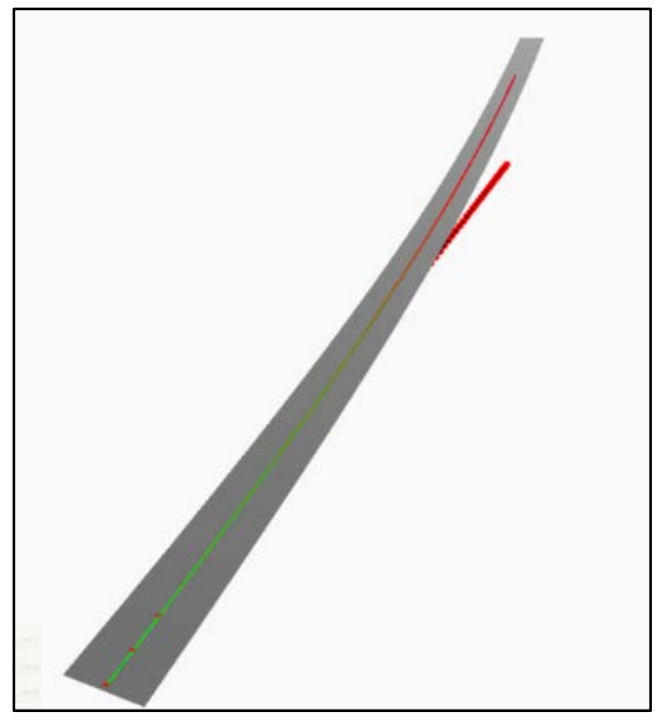

Figura 14 - Resultado visual

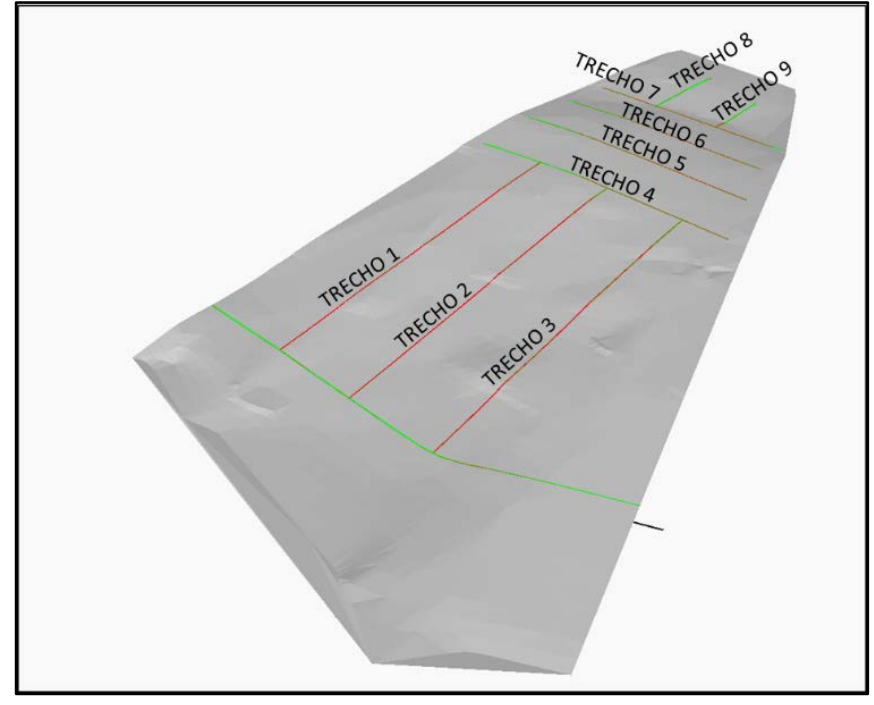

Tabela 1 - Dados exportados para planilha

\begin{tabular}{l|r|r|r|r|r|r|r|r|r|r|r}
\hline Inclin. (\%) & T-1 & \multicolumn{1}{|c|}{ T-2 } & \multicolumn{1}{|c|}{ T-3 } & T-4 & T-5 & \multicolumn{1}{|c|}{ T-6 } & T-7 & \multicolumn{1}{c}{ T-8 } & \multicolumn{1}{c|}{-9 } & \multicolumn{1}{c}{ Total } & \% \\
\hline$<3$ & 0,00 & 0,00 & 0,00 & 77,27 & 5,61 & 6,40 & 0,16 & 87,44 & 65,66 & 242,55 & 16,16 \\
\hline$\geq 3$ e $<5$ & 0,00 & 4,73 & 0,00 & 4,25 & 37,87 & 7,13 & 0,00 & 19,45 & 0,00 & 73,43 & 5 \\
\hline$\geq 5$ e $<8$ & 0,00 & 12,52 & 0,00 & 30,17 & 19,27 & 47,51 & 16,18 & 1,04 & 0,00 & 126,68 & 8 \\
\hline$\geq 8$ e $<10$ & 3,26 & 0,00 & 9,92 & 74,53 & 67,56 & 33,09 & 68,05 & 0,00 & 19,55 & 275,97 & 18 \\
\hline$\geq 10$ e $<12$ & 16,45 & 4,08 & 45,09 & 4,79 & 49,11 & 73,47 & 69,97 & 0,00 & 0,00 & 262,95 & 18 \\
\hline$\geq 12$ e $<15$ & 83,01 & 113,56 & 57,43 & 0,00 & 0,00 & 0,00 & 3,89 & 0,00 & 0,00 & 257,89 & 17 \\
\hline$\geq 15$ e $<20$ & 122,04 & 81,58 & 40,76 & 0,00 & 0,00 & 0,00 & 0,00 & 0,00 & 0,00 & 244,38 & 16 \\
\hline$\geq 20$ e $<25$ & 0,60 & 4,59 & 4,00 & 0,00 & 0,00 & 0,00 & 0,00 & 0,00 & 0,00 & 9,19 & 1 \\
\hline$\geq 25$ e $<30$ & 0,00 & 3,71 & 3,74 & 0,00 & 0,00 & 0,00 & 0,00 & 0,00 & 0,00 & 7,45 & 0,50 \\
\hline Total & $\mathbf{2 2 5 , 3 5}$ & $\mathbf{2 2 4 , 7 6}$ & $\mathbf{1 6 0 , 9 4}$ & $\mathbf{1 9 1 , 0}$ & $\mathbf{1 7 9 , 4 2}$ & $\mathbf{1 6 7 , 5 9}$ & $\mathbf{1 5 8 , 2 6}$ & $\mathbf{1 0 7 , 9 4}$ & $\mathbf{8 5 , 2 2}$ & $\mathbf{1 . 5 0 0 , 4 8}$ & $\mathbf{1 0 0}$ \\
\hline
\end{tabular}


Figura 15 - Gráfico resultante dos dados

$$
\begin{aligned}
& =<3 \% \\
& =\geq 3 \% \text { e }<5 \% \\
& =\geq 5 \% \text { e }<8 \% \\
& =\geq 8 \% \text { e }<10 \% \\
& =\geq 10 \% \text { e }<12 \% \\
& =\geq 12 \% \text { e }<15 \% \\
& =\geq 15 \% \text { e }<20 \% \\
& \square \geq 20 \% \text { e }<25 \% \\
& -\geq 25 \% \text { e }<30 \%
\end{aligned}
$$

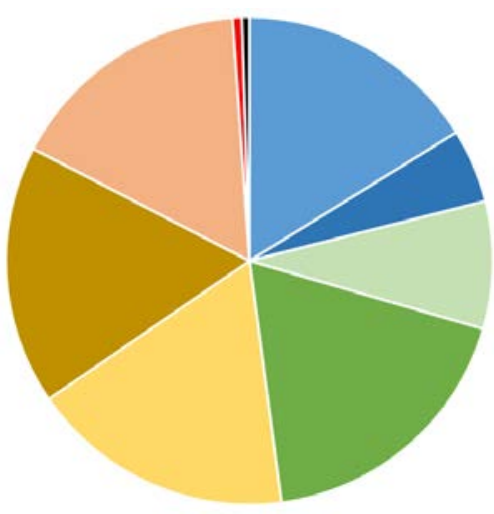

Figura16 - Algoritmo para determinar o tamanho do lote

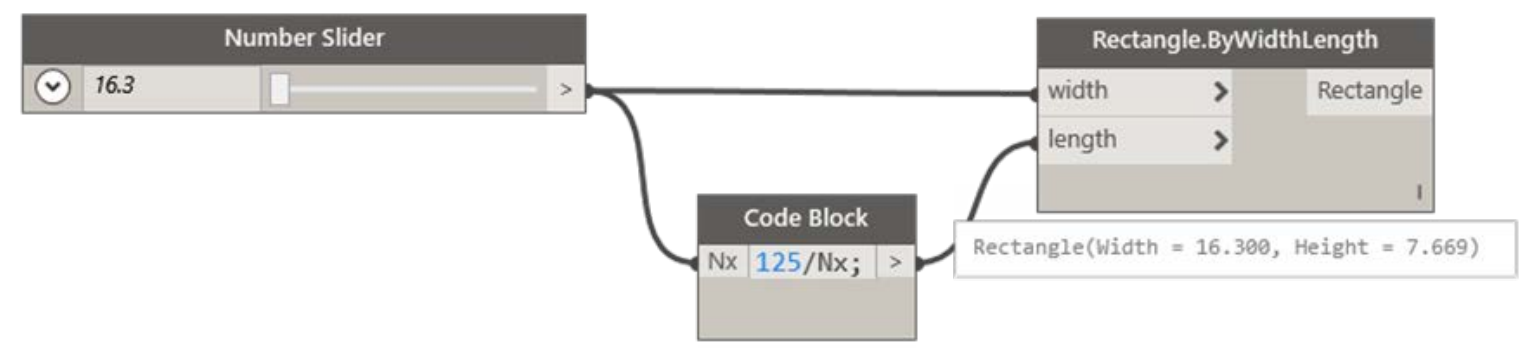

Nota: utilizando parâmetros para um lote mínimo: comprimento mínimo de m; largura mínima de 15 m; e área mínima de $125 \mathrm{~m}^{2}$. Foi criado um algoritmo simples para auxiliar na subdivisão das quadras em que se associou o comprimento variando (1), com a área mínima de $125 \mathrm{~m}^{2}$ (2) e resultando na largura (3).

Figura 17 - Novo lançamento de vias

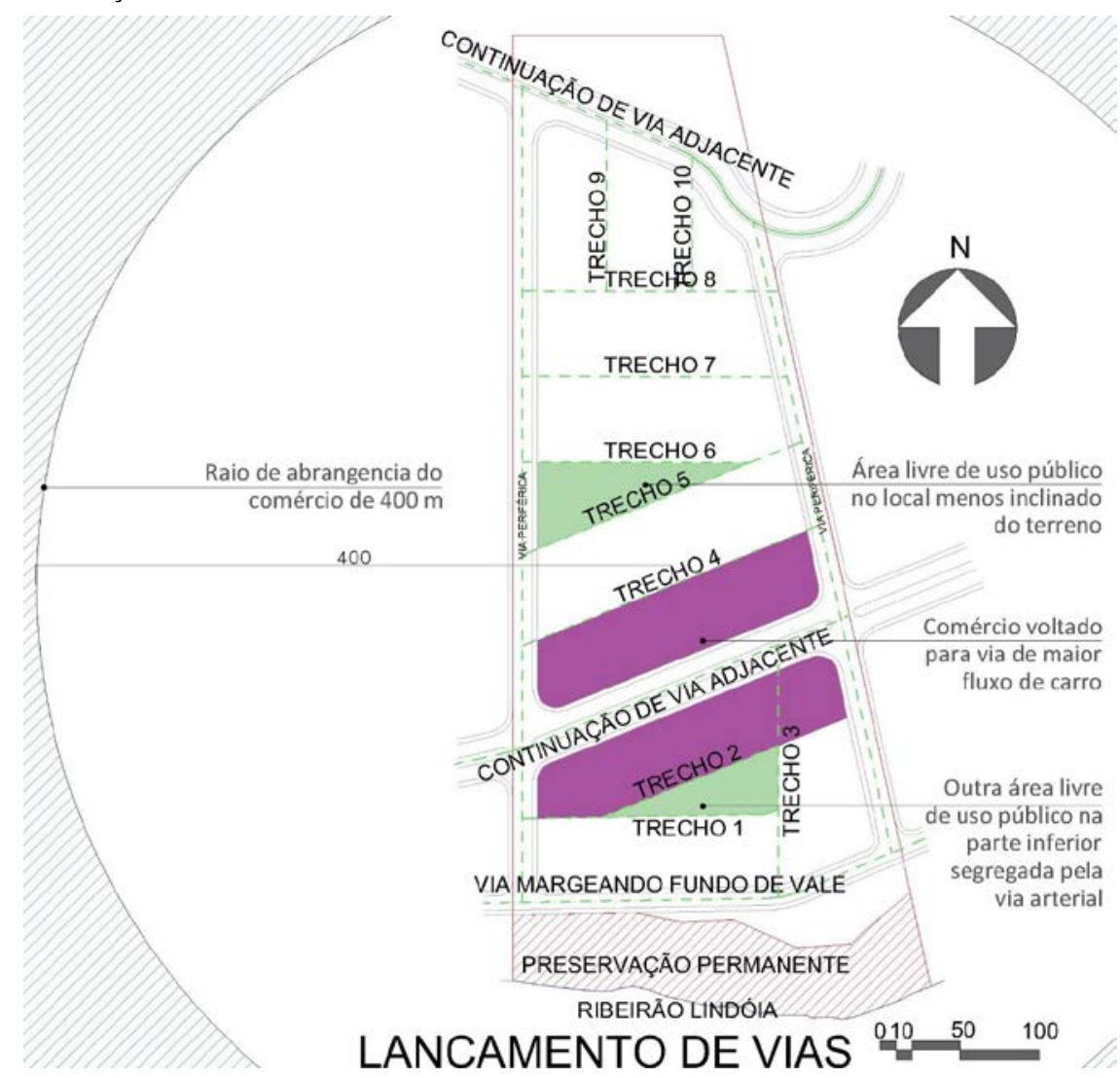


Esse novo lançamento resultou em vias mais planas, tendo apresentado $77,06 \%$ das vias com inclinação menor que $10 \%$, sendo que no primeiro caso era de 47,16\% (Tabela 2 e Figuras 18 e 19). Como o modelo associativo permite que modificações nos parâmetros das vias alterem de forma automática o resultado deste, é possível desenvolver simulações de diversos cenários tendo feedback visual e de impactos quantitativos de forma imediata. Além disso, permite a utilização desses números em planilhas de preços para o cálculo do custo.

\section{Tabela 2 - Dados exportados para planilha}

\begin{tabular}{l|r|r|r|r|r|r|r|r|r|r|r|r}
\hline \multicolumn{1}{c|}{ Inclin. (\%) } & \multicolumn{1}{c|}{ T-1 } & \multicolumn{1}{c|}{ T-2 } & T- 3 & \multicolumn{1}{|c|}{ T-4 } & \multicolumn{1}{c|}{ T-5 } & \multicolumn{1}{|c|}{ T-6 } & \multicolumn{1}{c|}{ T-7 } & \multicolumn{1}{c|}{ T-8 } & T- 9 & T-10 & \multicolumn{1}{c|}{ Total } & \% \\
\hline$<3$ & 81,92 & 49,94 & 0,00 & 36,87 & 39,41 & 5,61 & 6,40 & 6,30 & 87,44 & 65,66 & 379,56 & 25,20 \\
\hline$\geq 3$ e $<5$ & 47,41 & 60,50 & 0,00 & 36,03 & 37,42 & 37,87 & 7,13 & 0,00 & 19,45 & 0,00 & 245,80 & 16,32 \\
\hline$\geq 5$ e $<8$ & 18,35 & 3,32 & 0,00 & 112,20 & 44,95 & 19,27 & 47,51 & 16,18 & 1,04 & 0,00 & 262,82 & 17,45 \\
\hline$\geq 8$ e $<10$ & 12,58 & 8,20 & 9,92 & 5,82 & 62,42 & 52,86 & 33,09 & 68,05 & 0,00 & 19,55 & 272,50 & 18,09 \\
\hline$\geq 10$ e $<12$ & 0,87 & 0,00 & 45,10 & 11,72 & 6,12 & 28,47 & 73,47 & 69,97 & 0,00 & 0,00 & 235,72 & 15,65 \\
\hline$\geq 12$ e $<15$ & 0,00 & 0,00 & 57,43 & 0,00 & 0,00 & 0,00 & 0,00 & 3,89 & 0,00 & 0,00 & 61,32 & 4,07 \\
\hline$\geq 15$ e $<20$ & 0,00 & 0,00 & 40,76 & 0,00 & 0,00 & 0,00 & 0,00 & 0,00 & 0,00 & 0,00 & 40,76 & 2,71 \\
\hline$\geq 20$ e $<25$ & 0,00 & 0,00 & 4,00 & 0,00 & 0,00 & 0,00 & 0,00 & 0,00 & 0,00 & 0,00 & 4,00 & 0,27 \\
\hline$\geq 25$ e $<30$ & 0,00 & 0,00 & 3,74 & 0,00 & 0,00 & 0,00 & 0,00 & 0,00 & 0,00 & 0,00 & 3,74 & 0,25 \\
\hline Total (metros) & $\mathbf{1 6 1 , 1}$ & $\mathbf{1 2 2 , 0}$ & $\mathbf{1 6 1 , 0}$ & $\mathbf{2 0 2 , 6}$ & $\mathbf{1 9 0 , 3}$ & $\mathbf{1 4 4 , 1}$ & $\mathbf{1 6 7 , 6}$ & $\mathbf{1 6 4 , 4}$ & $\mathbf{1 0 7 , 9}$ & $\mathbf{8 5 , 2}$ & $\mathbf{1 . 5 0 6 , 2}$ & $\mathbf{1 0 0}$ \\
\hline
\end{tabular}

Figura 18 - Resultado visual da modificação

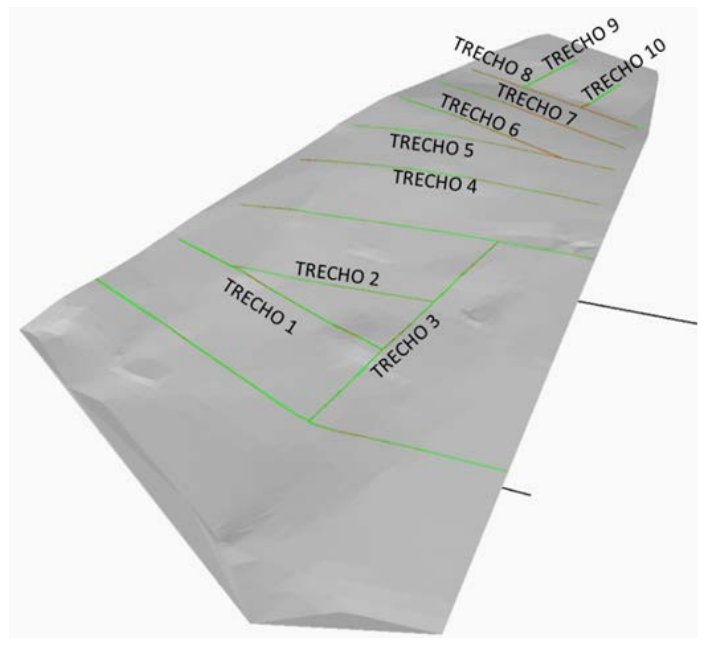

Figura 19 - Gráfico resultante dos dados
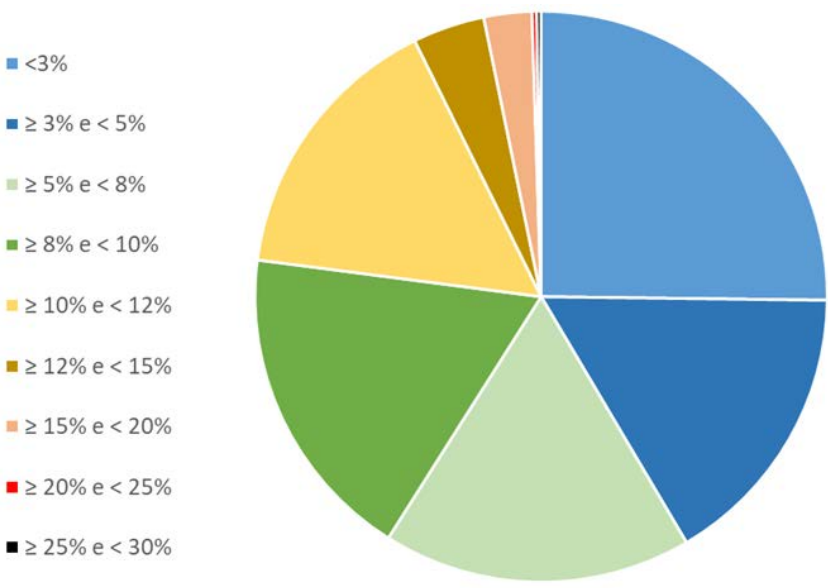
Neste estudo foram desenvolvidas apenas duas simulações para possibilitar a avaliação da utilidade e eficácia por parte de um profissional atuante no desenvolvimento de EHIS.

Para isso, assim que a via é selecionada pelo algoritmo, é identificada como um elemento importado do software Revit. De tal modo, a menos que a via selecionada seja deletada, é possível modificá-la no próprio Revit, deslocando, modificando seu tamanho e ângulo. Ao mesmo tempo, o algoritmo atualiza os resultados e planilhas de Excel sem a necessidade de recarregar a via ou atualizar planilhas manualmente.

\section{Análise de resultados}

O modelo foi avaliado em duas etapas: a primeira, feita pelos próprios autores no desenvolvimento e formulação do modelo; e a segunda, por um engenheiro civil, empresário, dedicado à produção de EHIS e responsável pelo empreendimento adotado como caso neste estudo. Esta última avaliação permitiu considerações quanto à utilidade do modelo, sua aplicabilidade e eficácia.

Ao longo do estudo verificaram-se os pontos a seguir:

(a) a princípio visava-se ao desenvolvimento de um modelo apenas para a visualização das relações entre topografia e sistema viário, na tentativa de gerar referências visuais, base do Visual Thinking descrito por Goldschmidt (2001) e Ware (2008). No entanto, durante a formulação dos algoritmos identificou-se a possível utilização do modelo para apoiar a escolha do terreno, proporcionando uma análise prévia da topografia. No caso de EHIS, essa análise também pode ser utilizada para monitoramento, planejamento e fiscalização por órgãos regulamentadores dos empreendimentos;

(b) o segundo algoritmo permitiu a visualização do comprimento e inclinação da via traçada, dois parâmetros diretamente relacionadas ao custo;

(c) a utilização do modelo associativo permitiu a visualização dos dados decorrentes desses projetos. E, como Terzidis (2003) coloca, o processamento de dados e de tarefas repetitivas feito pelo computador permitiu e facilitou modificações e ajustes do projeto de forma ágil e precisa;

(d) a coleta e a organização dos dados, antes mesmo da criação do modelo e da utilização das ferramentas digitais, mostraram-se fundamentais na problematização do projeto;

(e) os algoritmos e os modelos foram desenvolvidos em um período de aproximadamente 3 meses, e a aplicação do modelo para análise de um projeto pode ser feita em 1 dia. Contudo, deve-se observar que esses tempos de trabalho estão relacionados com o conhecimento prévio do pesquisador, mas que, com pouco tempo de treinamento, se pode alcançar resultados semelhantes;

(f) o artefato ficou limitado apenas à visualização da inclinação da topografia e vias: mesmo atendendo à legislação e aos referenciais qualitativos para o lançamento das vias, as possíveis consequências dessas vias nos lotes não foram analisadas, como a necessidade de muros de contenções e grandes taludes dentro do lote; e

(g) o modelo foi criado pensando na utilização por projetistas que não têm conhecimento das ferramentas de design associativo, de forma a facilitar a tomada de decisões e o lançamento do projeto pelo projetista. Para tanto, buscou-se a simplificação dos dados a serem inseridos no software, apenas com os eixos das vias. Contudo, em consonância com a lógica do design associativo (MEREDITH, 2008; NOJIMOTO;TRAMONTANO; ANELLI, 2001), essa simplificação inicial dos dados inseridos não impede que o modelo possa carregar ou adicionar posteriormente outras informações mais detalhadas do objeto, como calçada, via de rolagem e espessuras.

A avaliação pelo engenheiro civil foi realizada por meio de uma entrevista não estruturada em 12 de junho de 2017. Primeiramente foi apresentado o modelo, seu desenvolvimento, funcionamento, aplicações e resultados obtidos, para então o avaliador realizar as observações em relação a ele. $\mathrm{O}$ engenheiro considerou o modelo bastante útil para racionalizar o traçado das vias e, portanto, um suporte importante para o desenvolvimento do projeto de loteamento. O avaliador também destacou o valor do uso do modelo como auxiliar na seleção de terrenos para EHIS, um ponto crítico de sua viabilidade econômica. Seguem abaixo as considerações feitas pelo especialista:

(a) o modelo seria útil para negociação de terrenos, pois atualmente a avaliação da topografia é feita in loco e apenas visualmente. Ao ilustrar e visualizar os resultados do modelo, é possível ter dados para decidir sobre a aquisição ou não do terreno. $\mathrm{O}$ avaliador sugeriu a utilização de um coeficiente de depreciação para áreas com inclinações muito altas;

(b) a tecnologia empregada nesse modelo foi considerada muito aplicável: o empreendedor expressou o desejo de ver a evolução deste para outro que possa também gerar propostas de projeto das habitações; 
(c) destacou que o modelo seria uma ferramenta útil para órgãos fiscalizadores avaliarem projetos;

(d) o modelo seria muito útil para justificativas e exposição de propostas de empreendimentos para órgãos públicos;

(e) para o avaliador, a gradação mais importante de inclinação é a partir de $15 \%$, que é um limite exigido pelos órgãos públicos para as vias;

(f) o avaliador considerou necessário compreender de forma mais aprofundada o funcionamento dos algoritmos para permitir uma interpretação dos resultados de forma mais precisa; e

(g) o artefato deveria permitir utilizar dados topográficos de fontes como prefeitura municipal e Sketchup, pois, para a avaliação inicial de escolha de terrenos, dificilmente há levantamentos topográficos já realizados.

\section{Conclusões}

O trabalho tem como contribuição uma aplicação muito particular no desenvolvimento de um EHIS para as condições locais existentes da cidade Londrina, mas que podem ser aplicados em outros contextos desde que se façam adequações em seus parâmetros.

Os resultados obtidos indicam que o modelo desenvolvido permite que dados topográficos e custos de infraestrutura urbana sejam incorporados e analisados ainda em etapas iniciais do processo de desenvolvimento de um EHIS. Nesse sentido, os resultados gerados pelo modelo auxiliaram na análise de um projeto existente em um primeiro momento e também na tomada de decisão de projeto num segundo momento, assim como na justificativa dessas decisões. Como resultado, o projeto proposto conseguiu vias mais planas proporcionalmente, já que se obteve um aumento de cerca de $63 \%$ no total de vias com menos de $10 \%$ de inclinação. Também se viu a possibilidade da análise da topografia do terreno, que fornece argumentos também para a negociação de aquisição.

Embora o modelo proposto como ferramenta não garanta por si a qualidade do projeto, pois os resultados dependem dos lançamentos que alimentam o modelo e interpretações feitas pelo projetista, o modelo permite a comparação das propostas lançadas e a escolha, de maneira sistematizada, daquela que possui um traçado otimizado em termos de inclinação e tamanho de vias. Dessa forma, o modelo permite gerar loteamentos com melhor qualidade de vida e menor custo.
Ressalta-se também que modelos como este apresentado neste artigo podem ser desenvolvidos e utilizados na formação de profissionais, no sentido de promover a integração de diversos campos de conhecimento que abrangem projeto, topografia, planejamento urbano e viabilidade econômica para a tomada de decisão na escolha de terrenos.

\section{Referências}

ALVARADO, R. G.; MUÑOZ, J. J. The Control of Shape: origins of parametric design in architecture in Xenakis, Gehry and Grimshaw. METU Journal of the Faculty of Architecture, p. 107-118, 2012.

\section{ARAGÃO, D. L. L. J. Subsídios Para Aplicação do Custeio-Meta na Etapa de Concepção de Unidades Habitacionais de Interesse Social no Âmbito do PMCMV. Londrina, 2014. Dissertação (Mestrado em Arquitetura e Urbanismo) - Escola de Arquitetura, Universidade Estadual de Londrina, Londrina, 2014.}

\section{AYOUB, T. A. A. Conjuntos Habitacionais e}

Espaços Livres: correlações socioespaciais e orientações projetuais. Londrina, 2014.

Dissertação (Mestrado em Arquitetura e Urbanismo) - Escola de Aquitetura, Universidade Estadual de Londrina, Londrina, 2014.

CONCEIÇÃO, P. A. Método Para Classificação de Famílias Visando à Adoção da Customização em Massa por Segmentos na Habitação de Interesse Social. Londrina, 2015. Dissertação (Mestrado em Arquitetura e Urbanismo) - Escola de Arquitetura, Universidade Estadual de Londrina, Londrina, 2015.

DRESCH, A.; LACERDA, D. P.; ANTUNES, J. A. V. J. Design Science Research. Porto Alegre: Bookman, 2015.

GOLDSCHMIDT, G. Visual Analogy: a strategy for design reasoning and learning. In: EASTMAN, C.; MCCRACKEN, M.; NEWSTETTER, W. Design Knowing and Learning: cognition in design education. Oxford: Elsevier, 2001.

GROSS, M. D. Design as Exploring Constraints. Cambridge: MIT Press, 1985.

JOHNSON, G. et al. Computational Support for Sketching in Design: a review. Foundations and Trends in Human-Computer Interaction, v. 2, n. 1, p. 1-93, 2008. 
KOLAREVIC, B. Digital Architectures.

ACADIA 2000: eternity, infinity and virtuality. Washington: Association for Computer-Aided Design in Architecture, 2000.

LAWSON, B. Como Arquitetos e Designers Pensam. São Paulo: Oficina de Textos, 2011.

LUKKA, K. The Constructive Research Approach. In: OJALA, L.; HILMOLA, O.-P. Case Study Research in Logistics. Turku: Publications of the Turku School of Economics and Business Administration, 2003.

MARCH, S. T.; SMITH, G. F. Design and Natural Science Research on Information Technology. Decision Support Systems, v. 15, p. 251-266, 1995.

MEREDITH, M. From Control to Design. New York: Actar-D, 2008.

NOJIMOTO, C.; TRAMONTANO, M.; ANELLI, R. L. S. Design Paramétrico. In: CONGRESO SIGRADI, 15., Santa Fé, 2011. Anales... Facultad de Arquitectura, Diseño y Urbanismo, Universidad Nacional del Litoral, 2011.

OOSTERHUIS, K. et al. File to Factory and Real Time Behavior in ONL-Architecture. In: Annual Conference of the Association for Computer Aided Design in Architecture, 23.; Conference of the AIA Technology in Architectural Practice Knowledge Community, Cambridge, 2004. Proceedings... Cambridge, 2004.

OXMAN, R. Theory and Design in the First Digital Age. Design Studies, p. 229-265, 2005.

RITTEL, H. W. J.; WEBBER, M. M. Dilemmas in a General Theory of Planning. Policy Sciences, v. 4, n. 2, p. 155-169, 1973.

SAITO, C. Estudo Para a Determinação dos Custos-Meta em Empreendimentos Habitacionais de Interesse Social no Programa Minha Casa, Minha Vida. Londrina, 2016. Dissertação (Mestrado em Arquitetura e Urbanismo) - Universidade Estadual de Londrina, Londrina, 2016.
SCHÖN, D. The Reflective Practitioner. New York: Basic Books, 1983.

SHIGUEHARU, M. A. O Senso de Comunidade no Conjunto Habitacional São Lourenço Londrina - PR. Londrina, 2015. Dissertação (Mestrado em Arquitetura e Urbanismo) Universidade Estadual de Londrina, Londrina, 2015.

SIMON, H. A. The Sciences of the Artificial. Cambridge: The MIT Press, 1969.

TERZIDIS, K. Expressive Form: a conceptual approach to computational design. London and New York: Spon, 2003.

TZORTZOPOULOS, P. Contribuições Para o Desenvolvimento de Um Modelo do Processo de Projeto de Edificações em Empresas Construtoras Incorporadoras de Pequeno Porte. Porto Alegre, 1999. Dissertação (Mestrado em Engenharia Civil) - Escola de Engenharia, Universidade Federal do Rio Grande do Sul, Porto Alegre, 1999.

VICENTIM, T. N. Análise do Comércio e Serviço nos Empreendimentos do Programa Minha Casa, Minha Vida: estudo de caso do Residencial Vista Bela. Londrina, 2015.

Dissertação (Mestrado em Arquitetura e Urbanismo) - Universidade Estadual de Londrina, Londrina, 2015.

VOORDT, T. V. D.; WEGEN, H. B. R. Architecture in Use: an introduction to the programming, design and evaluation of buildings. Oxford: Elsevier; Architectural Press, 2005.

WARE, C. Visual thinking for design. Burlington. Elsevier, 2008.

\section{Agradecimentos}

Os autores agradecem à CAPES e ao CNPq, por financiar esta pesquisa, e ao engenheiro civil e sua empresa, pela disponibilização de material para pesquisa e tempo para avaliação do modelo. 


\section{Flávio Akihiro Takahashi}

Departamento de Construção Civil, Centro de Tecnologia e Urbanismo | Universidade Estadual de Londrina | Rodovia Celso Garcia Cid, PR 445, km 380, J ardim Sabará I| Londrina - PR - Brasil | Caixa Postal 6001 | CEP 86051-970 | Tel.: (43) 3325-8293 | E-mail:

flavio.nasu@gmail.com

\section{Ercilia Hitomi Hirota}

Departamento de Construção Civil, Centro de Tecnologia e Urbanismo | Universidade Estadual de Londrina | Tel.: (43) 3371-4460 |

E-mail: ercilia@uel.br

Rovenir Bertola Duarte

Departamento de Construção Civil, Centro de Tecnologia e Urbanismo | Universidade Estadual de Londrina | Tel.: (43) 3371 -4535 |

E-mail: rovenir@uel.br

\section{Revista Ambiente Construído}

Associação Nacional de Tecnologia do Ambiente Construído

Av. Osvaldo Aranha, 99 - 3o andar, Centro

Porto Alegre - RS - Brasil

CEP $90035-190$

Telefone: +55 (51) 3308-4084

Fax: +55 (51) 3308-4054

www. seer. ufrgs. br/ ambienteconstruido

E-mail: ambienteconstruido@ufrgs.br

(c) (i)

This is an open-access article distributed under the terms of the Creative Commons Attribution License. 